\title{
Lightning protection of communication sites: revisited
}

\begin{abstract}
In this paper we analyze the lightning protection system of 48 communication and broadcasting towers situated in similar isokeraunic contours in Sri Lanka. The results show that a direct strike to an antenna structure in a metallic tower is rare irrespective of the presence of an air-termination or a down conductor. However, side flashing or arcing to antenna structures is highly possible once the air-termination and/or down conductor is installed and attempts are made to insulate the system from the tower. The outcome also shows that equipotential bonding of the grounding system, a distributed grounding network including a ring conductor and a suitable system of surge protective devices play a much more vital role in lightning protection of equipment and safety of people than simply achieving a low grounding resistance. However, in the absence of such integrated, distributed and equipotentialized grounding system, a high value of ground resistance sharply increases the possibility of accidents and damage. Considering the observations of the investigations into account we have designed a concrete embedded grounding system for tower sites at problematic locations with respect to ground resistivity. The system performance has been tested by implementing the system at two tower sites and observing the performance for 3 years.
\end{abstract}

